\title{
Motivational interviewing for adherence: post- training attitudes and perceptions of physicians who treat asthma patients
}

This article was published in the following Dove Press journal:

Patient Preference and Adherence

2I April 2017

Number of times this article has been viewed

\author{
Miguel Román-Rodríguez' \\ Lara Ibarrola-Ruiz ${ }^{2}$ \\ Fernando Mora ${ }^{3}$ \\ Vicente Plaza ${ }^{4}$ \\ Joaquín Sastre ${ }^{5}$ \\ Alfonso Torrego 4 \\ José María Vega ${ }^{6}$ \\ Guadalupe Sánchez- \\ Herrero ${ }^{2}$ \\ 'Centro de Salud Son Pisà, IB-Salut, \\ Balearic Health Service, Unidad \\ de investigación en enfermedades \\ crónicas respiratorias en atención \\ primaria, Instituto de Investigación \\ Sanitaria de Baleares (IdISBa), Palma \\ de Mallorca, ${ }^{2} \mathrm{GSK},{ }^{3}$ Department \\ of Psychiatry, Hospital Infanta \\ Leonor, Madrid, ${ }^{4}$ Department of \\ Respiratory Medicine, Hospital de \\ la Santa Creu i Sant Pau, Institut \\ d'Investigació Biomédica Sant Pau (IIB \\ Sant Pau), Universitat Autònoma de \\ Barcelona, Barcelona, ${ }^{5}$ Department \\ of Allergology, Fundación Jimenez \\ Díaz y Universidad Autónoma de \\ Madrid, CIBER de Enfermedades \\ Respiratorias, Ministerio de Economía \\ y Competitividad, Madrid, ${ }^{6}$ Unidad \\ de Gestión Clínica de Alergología, \\ Hospital Regional Universitario de \\ Málaga, Málaga, Spain
}

Correspondence: Miguel Román-Rodríguez Centro de Salud Son Pisà, C/De Vicenç Joan Rossello Ribas, No 65,

070I I Palma de Mallorca, Spain

Tel +34 97 I63 4II5

Email miguelroman@ibsalut.caib.es
Objective: The aim of this study was to evaluate the attitudes and perceptions of health care professionals (HCPs) who have been trained in motivational interviewing (MI) to improve adherence. Another objective of this study was to compare groups of HCPs with different levels of training in adherence (trained vs untrained; previous training in adherence education [AdhE] vs specific training in MI).

Methods: For this study, a national questionnaire-based survey was conducted among HCPs treating asthma. A total of 360 HCPs were surveyed (allergists: $n=110$; pulmonologists: $n=120$; general practitioners: $\mathrm{n}=130$ ). Of them, 180 physicians had received a training intervention (training in AdhE: $n=90$; training in $\mathrm{MI}$ to promote adherence: $\mathrm{n}=90$ ).

Results: Of the total surveyed HCPs, $92.8 \%$ reported adherence is highly important in asthma control. More professionals trained in MI compared to those trained in AdhE considered that "simplifying treatment as far as possible" $(85.6 \%$ vs $68.9 \%, P=0.0077)$, "involving the patient in treatment plans" ( $85.6 \%$ vs $71.1 \%, P=0.0187)$, "giving the patient self-care patterns" $(52.2 \%$ vs $36.7 \%, P=0.0357)$ and "performing MI" $(42.2 \%$ vs $15.6 \%, P<0.0001)$ were the most important interventions to promote adherence. "Empathy between doctor and patient" $(93.3 \% \mathrm{vs}$ $77.8 \%, P=0.0036)$ and "concordance of medical and patient treatment goals" ( $96.7 \%$ vs $72.2 \%$, $P<0.0001$ ) were the factors perceived as having the greatest influence in improving adherence to asthma treatment by the physicians in the MI group as opposed to those in the AdhE group. The use of MI in asthma consultation was the most highly valued resource to promote adherence to treatment among all the professionals, particularly those who had received specific MI training compared to those who had received any kind of previous training in AdhE $(96.7 \%$ vs $66.7 \%, P<0.0001)$.

Conclusion: MI is considered an important tool to promote adherence to asthma treatment among HCPs, especially among those specifically trained in that aspect. MI training interventions seem to influence HCPs' approaches to improve self-care and to engage patients in treatment plans rather than approaches solely centered on AdhE.

Keywords: asthma, adherence, control, training, motivational interviewing, education

\section{Introduction}

Medication adherence is considered to be a key factor in asthma control, ${ }^{1,2}$ and nonadherence is associated with increased asthma symptoms, ${ }^{3}$ uncontrolled asthma, ${ }^{4,5}$ frequent emergency department visits, ${ }^{4}$ hospitalizations ${ }^{6}$ and higher health care utilization and costs. ${ }^{7,8}$

Recent guidelines ${ }^{9-11}$ specifically recommend the evaluation and follow-up of patient medication adherence, although it continues to be a difficult goal, and adherence rates 
in asthma are still consistently low, ranging from 30\% to $70 \%$ overall and from $30 \%$ to $40 \%$ in clinical practice settings. ${ }^{12,13}$ Promoting adherence in asthma remains a goal that requires a considerable effort from health care providers. ${ }^{14}$

Several training interventions for health care providers have been implemented to promote adherence and have been extensively evaluated in pathologies such as hypertension, ${ }^{15}$ diabetes ${ }^{16}$ and HIV. ${ }^{17}$ Some of these training interventions primarily target health care providers, and range from simple "educational interventions" to more complex "behavioral interventions". Recent studies have evaluated cognitivebased techniques to change behaviors as interventions to improve medication adherence. ${ }^{18,19}$

Behavioral interventions are "patient-centered" strategies where the health care provider tries to understand the patient's expectations, beliefs and concerns regarding his/her health and the recommended treatments, thereby facilitating behavioral change and seeking to treat not just the illness but the patient as a whole. ${ }^{20}$ Behavioral intervention strategies are increasingly being used in adherence support interventions, and doctors should be trained to increase their capacities in this field.

Motivational interviewing (MI) is a tool designed to facilitate behavioral change in the patient by resolving the ambivalence to change. ${ }^{21}$ This tool therefore primarily targets intentional nonadherence, although it also enables patients to reflect upon any unintentional barriers to remain adherent to treatment and to seek solutions. Several meta-analyses have reported the efficacy of MI in facilitating health-related behavioral change in substance abuse, such as tobacco, alcohol and others. ${ }^{22-24}$ Currently, only two studies have been performed by general practitioners that specifically analyzed the feasibility of MI in promoting adherence in asthma. ${ }^{25,26}$ However, both of them were limited by a small sample size. Moreover, the possible impact of different training interventions on improving HCPs' skills in changing behaviors of nonadherent asthma patients has not been previously assessed.

The aim of this study was to explore the attitudes and perceptions of HCPs after being trained in MI on adherence and to compare groups of HCPs with different levels of training in adherence.

\section{Methods}

\section{Design of the study}

To avoid the possible bias of previous educational interventions on adherence and to understand the possible effect of these interventions, a study with two phases was designed: First, an opinion-based survey was conducted to assess the starting level of the interviews. Second, an MI educational intervention training was developed for a group of HCPs, and their opinions were assessed and compared to a control group. The opinion-based survey was conducted among different medical specialists (allergists, pulmonologists and general practitioners [GPs]) in Spain. Medical specialists who were responsible for the management of patients with asthma and who worked mainly (more than $60 \%$ of their practice) in the universally accessed public health care system were included. As an additional inclusion criterion, pulmonologists and allergists were required to visit at least 5 and 15 asthma patients a week, respectively, to ensure a minimum clinical experience in asthma management.

\section{Sample selection}

Participants were selected through a large pre-recruited panel, with access to people willing to participate. A questionnaire was administered to these participants to check fulfillment of the inclusion criteria. Only those who fulfilled the criteria were included in the study.

The sample size was appropriate to provide statistical significance to the results and to ensure statistical representation of the data provided: accepting a confidence level of 0.95 for a precision of \pm 0.07 units in a two-sided test for an estimated proportion of 0.5 (maximum uncertainty), a sample size of 180 subjects selected in each phase of the study from the whole population was required, assuming that such a population is infinite. A 0.05 two-sided significance level was set.

The sample selection was made taking into consideration the target populations. When each quota was completed, no further respondents were allowed to participate. All participants were duly informed of why they were chosen for this study, the main objective of the research and the type of intervention.

\section{Study procedures}

The study was carried out in two phases (Figure 1).

\section{Phase I}

In Phase I, a sample of 180 participants was recruited. Half of them had previously received some kind of training in adherence (distance learning courses, printed material, videos, images, or social media, among others) (adherence education [AdhE] group, $\mathrm{n}=90$ ); the other 90 participants had never been trained in adherence (control group 1, $\mathrm{n}=90$ ). They all answered an online quantitative survey between 6 March and 1 April 2015.

The online quantitative survey consisted of different sections (described in the "Questionnaire on adherence in 


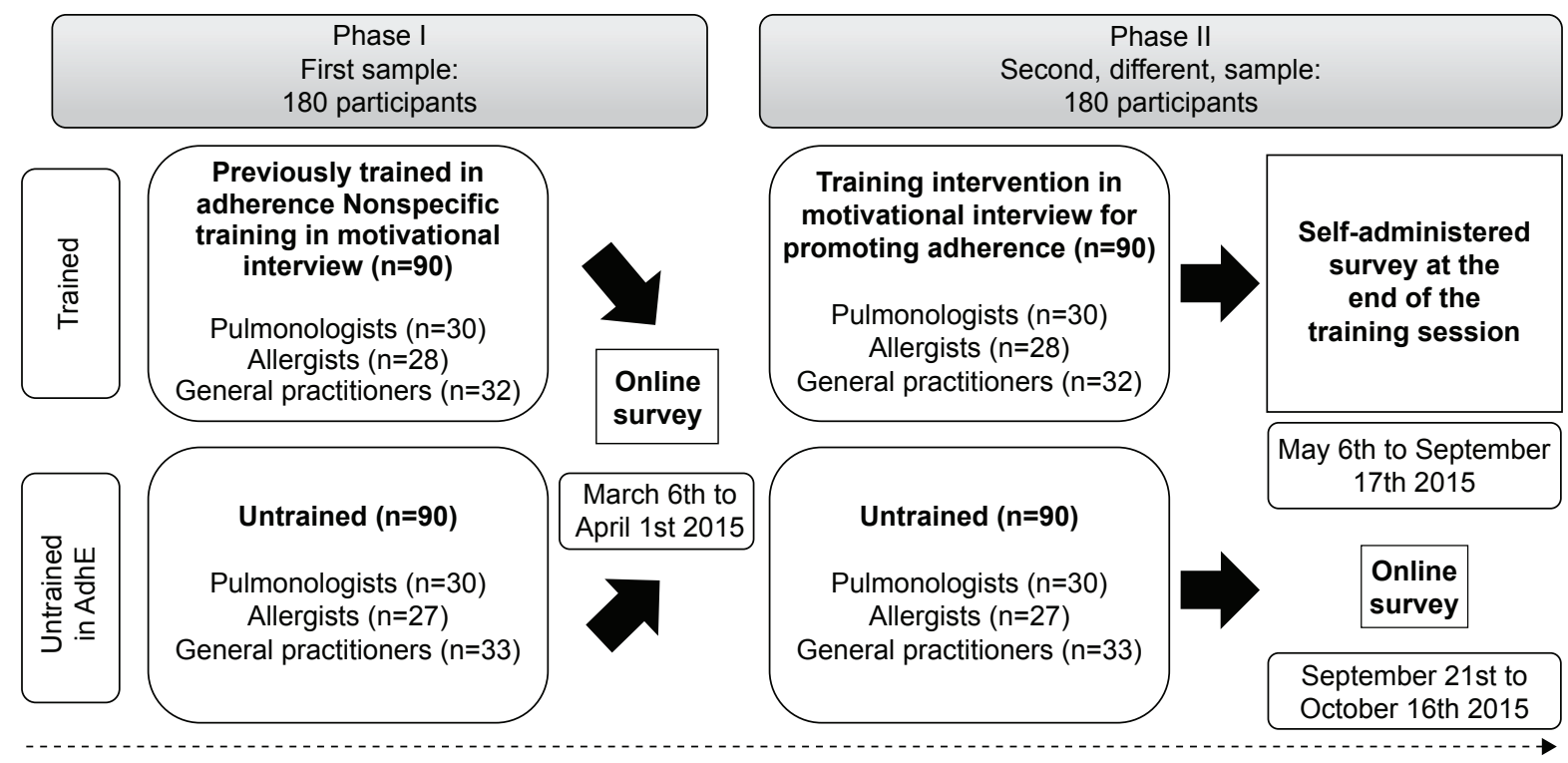

Figure I Study procedures.

Notes: Comparison groups: Professionals trained $(n=180)$ vs untrained in AdhE $(n=180)$. Previous training in AdhE $(n=90)$ vs specific training in motivational interview ( $n=90)$. Training in adherence: distance learning courses, printed material, videos, images, and social media, among others.

Training intervention in motivational interview: 2.30 -hour-long training sessions for medical professionals including: asthma adherence evidence-based theoretical training, training in motivational interview for promoting adherence to asthma treatment and practical discussion about a virtual case using video support. The training in motivational interview was conducted by a psychiatrist specialized in this type of technique.

Untrained in AdhE: no previous training in adherence.

Abbreviation: AdhE, adherence education.

asthma patients" section). The HCP answered the questionnaire based on his/her attitudes and perceptions. No clinical information was provided, and no written informed consent was required.

\section{Phase II}

In Phase II, a separate sample of 90 participants with no previous training in adherence was recruited as the control group (control group 2, $\mathrm{n}=90$ ). Specific training in MI to promote adherence in asthma was carried out between 6 May and 17 September 2015. Ninety physicians were recruited after attending this specific training, which was based on motivational tools and was aimed to help the physicians to encourage patient adherence during day-to-day consultations. ${ }^{11,27,28}$ The MI consisted of a 2.5-hour-long training session for medical professionals that included evidence-based asthma adherence theoretical training, training in MI to promote adherence to asthma treatment and open discussion about a virtual practical case using video support. The training in MI was conducted by a psychiatrist specialized in this type of methodology.

A quantitative self-administered survey (maximum 20 minutes) was given at the end of each MI training session. Untrained participants $(n=90)$ completed an online quantitative survey between 21 September and 16 October 2015.

\section{Questionnaire on adherence in asthma patients}

The Scientific Committee formed by a pulmonologist, an allergist and a family physician designed the survey questionnaire that was used in Phases I and II to assess four key topics in adherence: 1) current practice regarding adherence to asthma treatment; 2) factors positively or negatively influencing adherence to asthma treatment; 3 ) adherence and its impact on asthma control; 4) usual recommendations for improving asthma control and promoting adherence. In addition to responses to questions on these four topics, sociodemographic and professional data were also collected.

Each question was scored according to a five-point Likerttype scale and was then included in one of three categories: (1-2) least important (minor importance, low influence, unhelpful), (3) neutral and (4-5) most important (major importance, high influence, useful). ${ }^{29}$

\section{Statistical analysis}

The analysis was carried out using Phases I and II study data.

The groups were compared as follows:

1. Trained $(n=180)$ and untrained $(n=180)$ professionals were compared in order to analyze the differences among these clinicians based on presence or absence of previous training in adherence. 
2. Professionals with some kind of previous training in adherence $(n=90)$ were compared with those with specific training in MI $(n=90)$ with the objective of measuring possible differences between two different trainings.

The homogeneity of the untrained group (control group) between the Phases I and II was analyzed, and no statistically significant differences were observed.

Categorical variables were summarized with counts and percentages. For continuous variables, the number of nonmissing observations, mean, standard deviation, standard error of the mean, $95 \%$ confidence interval of the mean, median, first and third quartiles and minimum and maximum were tabulated. When applicable, these summaries were provided by trained vs untrained professionals and those trained in AdhE vs those trained in MI.

The statistical comparison between groups was performed using chi-squared or Fisher's exact test for categorical variables and Mann-Whitney-Wilcoxon/ Kruskal-Wallis tests, if the assumption of normality was not met, for quantitative variables. The KolmogorovSmirnov test was used to assess if quantitative variables followed a normal distribution. A 0.05 two-sided significance level was set.

The data analysis was performed using SAS/STAT ${ }^{\circledR}$ software, Version 9.2, of the SAS System for Windows. Copyright (c) 2002-2008 SAS Institute Inc., Cary, NC, USA. SAS and all other SAS Institute Inc. product or service names are registered trademarks or trademarks of SAS Institute Inc., Cary, NC, USA.

\section{Results Description of the participants}

A total of 360 participants were interviewed (allergists: $\mathrm{n}=110$; pulmonologists: $\mathrm{n}=120$; GPs: $\mathrm{n}=130$ ), of whom 180 had received training in MI $(\mathrm{n}=90)$ or some other kind of training in $\operatorname{AdhE}(\mathrm{n}=90)$, and 180 participants had not received any training (untrained controls). The sociodemographic and professional characteristics of the participants in each group are shown in Tables 1 and 2.

\section{Trained vs untrained professionals}

Clinical practice and adherence

Of all the surveyed HCPs, $92.8 \%$ reported adherence is highly important in asthma control. "More time for consultation" was reported by most professionals ( $88.6 \%$ ) as the main useful action related to resources to improve adherence. A "lack of time" was reported as the main reason for not evaluating adherence in all the groups. Most professionals (87.5\%) directly asked the patients (and/or caregivers) to assess adherence, while the use of standardized tests reported was scant, with no significant differences between groups. "Simplifying the treatment as far as possible" and "involving the patient in the treatment plan" were the most common procedures reported to encourage adherence to asthma treatment. The attitudes of trained doctors were significantly more favorable to MI and to offer health education to patients (Figure 2) (Supplementary materials).

\section{Factors affecting adherence}

Participants considered "patients involvement in understanding their illness" (94.1\%) as the most important aspect to

Table I Characteristics of trained and untrained participants

\begin{tabular}{|c|c|c|c|c|c|}
\hline Variable & Category & $\begin{array}{l}\text { Total } \\
(n=360)\end{array}$ & $\begin{array}{l}\text { Untrained } \\
(n=180)\end{array}$ & $\begin{array}{l}\text { Trained } \\
(n=180)\end{array}$ & $\begin{array}{l}\text { Differences } \\
\text { between groups }\end{array}$ \\
\hline \multirow[t]{2}{*}{ Gender } & Male & $196(54.4 \%)$ & 107 (59.4\%) & $89(49.4 \%)$ & 0.0568 \\
\hline & Female & $164(45.6 \%)$ & $73(40.6 \%)$ & $91(50.6 \%)$ & \\
\hline \multirow[t]{3}{*}{ Age (years) } & $<40$ & $85(23.6 \%)$ & $30(16.7 \%)$ & $55(30.6 \%)$ & $0.0060 * *$ \\
\hline & $40-50$ & II4 (31.7\%) & $59(32.8 \%)$ & $55(30.6 \%)$ & \\
\hline & $>50$ & I6I (44.7\%) & $91(50.6 \%)$ & 70 (38.9\%) & \\
\hline \multirow[t]{3}{*}{ Years of experience } & $<10$ & $62(17.2 \%)$ & $23(12.8 \%)$ & 39 (2I.7\%) & $0.0498 *$ \\
\hline & $10-20$ & I43 (39.7\%) & 71 (39.4\%) & 72 (40.0\%) & \\
\hline & $>20$ & $155(43.1 \%)$ & $86(47.8 \%)$ & $69(38.3 \%)$ & \\
\hline \multirow[t]{3}{*}{ Workplace } & Primary health care center & 127 (35.3\%) & $64(35.6 \%)$ & $63(35.0 \%)$ & 0.7964 \\
\hline & Specialty center & $21(5.8 \%)$ & $9(5.0 \%)$ & $12(6.7 \%)$ & \\
\hline & Hospital & $212(58.9 \%)$ & 107 (59.4\%) & 105 (58.3\%) & \\
\hline \multirow[t]{6}{*}{ Training } & $\mathrm{MI}$ & $97(26.9 \%)$ & - & 97 (53.9\%) & NA \\
\hline & Distance learning courses & 39 (10.8\%) & - & 39 (21.7\%) & NA \\
\hline & Printed material & $89(24.7 \%)$ & - & $89(49.4 \%)$ & NA \\
\hline & Videos or images & 51 (14.2\%) & - & 51 (28.1\%) & NA \\
\hline & Social media & 14 (3.9\%) & - & 14 (7.8\%) & NA \\
\hline & Others & 38 (10.6\%) & - & 38 (21.1\%) & NA \\
\hline Option that best suits you & & $164(45.6 \%)$ & - & I 64 (9I.1\%) & NA \\
\hline
\end{tabular}

Notes: Chi-squared test was applied; statistically significant: $* P<0.05$ and $* * P<0.01$.

Abbreviations: MI, motivational interviewing; NA, not applicable. 
Table 2 Characteristics of participants trained in adherence and those trained in motivational interview

\begin{tabular}{|c|c|c|c|c|c|}
\hline Variables & Category & $\begin{array}{l}\text { Total } \\
(n=180)\end{array}$ & $\begin{array}{l}\text { Trained in } \\
\text { AdhE }(n=90)\end{array}$ & $\begin{array}{l}\text { Trained in } \\
\text { MI }(n=90)\end{array}$ & $\begin{array}{l}\text { Differences } \\
\text { between groups }\end{array}$ \\
\hline \multirow[t]{2}{*}{ Gender } & Male & 89 (49.4\%) & $52(57.8 \%)$ & 37 (4I.l\%) & $0.0253^{*}$ \\
\hline & Female & $91(50.6 \%)$ & 38 (42.2\%) & $53(58.9 \%)$ & \\
\hline \multirow[t]{3}{*}{ Age (years) } & $<40$ & $55(30.6 \%)$ & $22(24.4 \%)$ & $33(36.7 \%)$ & 0.1179 \\
\hline & $40-50$ & $55(30.6 \%)$ & 27 (30.0\%) & $28(31.1 \%)$ & \\
\hline & $>50$ & 70 (38.9\%) & $4 \mathrm{l}(45.6 \%)$ & $29(32.2 \%)$ & \\
\hline \multirow[t]{3}{*}{ Years of experience } & $<10$ & $39(21.7 \%)$ & $16(17.8 \%)$ & $23(25.6 \%)$ & 0.1221 \\
\hline & $10-20$ & $72(40.0 \%)$ & $33(36.7 \%)$ & 39 (43.3\%) & \\
\hline & $>20$ & $69(38.3 \%)$ & $4 \mathrm{l}(45.6 \%)$ & $28(31.1 \%)$ & \\
\hline \multirow[t]{3}{*}{ Workplace } & Primary health care center & $63(35.0 \%)$ & $33(36.7 \%)$ & 30 (33.3\%) & 0.6997 \\
\hline & Specialty center & $12(6.7 \%)$ & 7 (7.8\%) & $5(5.6 \%)$ & \\
\hline & Hospital & $105(58.3 \%)$ & $50(55.6 \%)$ & 55 (6I.I\%) & \\
\hline \multirow[t]{6}{*}{ Training } & MI & 97 (53.9\%) & $7(7.8 \%)$ & $90(100 \%)$ & $<0.0001 * * *$ \\
\hline & Distance learning courses & 39 (21.3\%) & 31 (34.4\%) & $8(8.9 \%)$ & $<0.000$ I*** \\
\hline & Printed material & 89 (49.4\%) & $56(62.2 \%)$ & $33(36.7 \%)$ & $0.0006 * *$ \\
\hline & Videos or images & $5 \mathrm{I}(28.3 \%)$ & $14(15.6 \%)$ & 37 (4I.I\%) & $0.0001 * * *$ \\
\hline & Social media & 14 (7.8\%) & $8(8.9 \%)$ & $6(6.7 \%)$ & 0.5778 \\
\hline & Others & 38 (21.1\%) & $23(25.6 \%)$ & $15(16.7 \%)$ & 0.1440 \\
\hline Option that best suits you & & 164 (91.1\%) & 78 (86.7\%) & $86(95.6 \%)$ & $0.036 I^{*}$ \\
\hline
\end{tabular}

Notes: Chi-squared test was applied; statistically significant: $* P<0.05$, $* * P<0.01$ and $* * * P<0.001$.

Abbreviations: AdhE, adherence education; MI, motivational interviewing.

Involve the patient in the therapeutic plan

Simplify the treatment as far as possible

Give written information to the patient

Impart health education (inhalation techniques, etc.)

Involvement of family/patient environment

Give self-care guideline to the patient

Motivational interview

A specific program for asthma education

Use reminder methods

I call the patient if he/she did not turn up for the follow-up Note: $* P<0.05$.

Figure 2 Interventions to promote adherence in trained and untrained participants.

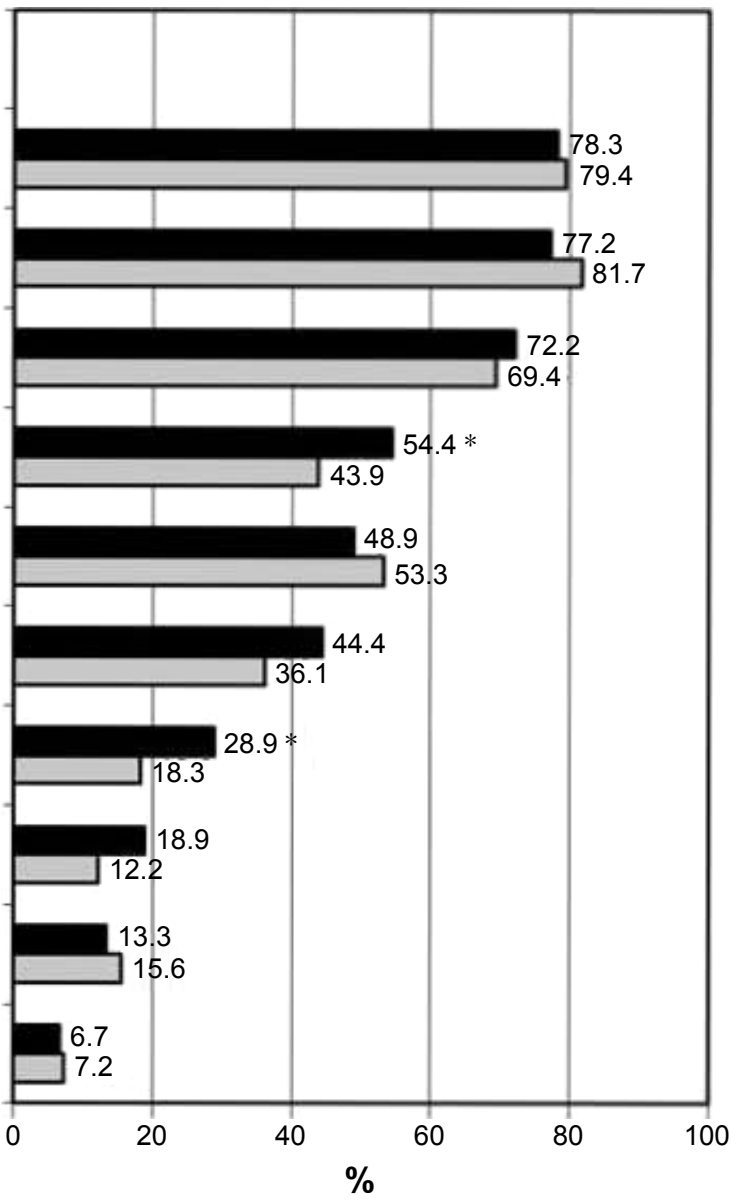

Trained $\square$ Untrained 
improve adherence to asthma treatment. Other important factors reported were "patient understanding of the risks and benefits of treatment" (91.1\%), "easy device use" (90.6\%), "simple dosing regimen" (86.9\%), "correct use of inhaler device" (85.3\%) and "empathy between physician and patient" $(83.1 \%)$. The trained professionals considered "concordance in therapeutic targets between doctor and patient" to be more important than the untrained professionals $(84.4 \%$ vs $71.1 \%, P=0.0082$ ) (Supplementary materials).

Adherence and its impact on asthma control (areas affected)

The "improvement of patients' daily activities" (93.6\%) was the aspect that participants considered would be most affected by improved adherence to asthma treatment. No statistically significant differences between trained and untrained participants were reported in any question on this subject (Supplementary materials).

Recommendations to improve control of asthma and promote adherence to treatment (useful actions)

HCPs reported barriers to developing adherence interventions in asthma patients and possible solutions to solve them. These included increasing the time for management visits, encouraging collaborative treatment, promoting MI and simplifying drug regimens. Most participants $(88.6 \%)$ reported that an increase in consultation time would improve the control and promotion of adherence. The training did not significantly affect the perceptions as to which actions were useful for physicians for improving adherence, except in the use of videos and images (Supplementary materials).

\section{Professionals with some kind of previous training in adherence vs those with specific training in $\mathrm{Ml}$ to promote adherence}

A large majority of professionals who had received specific training in $\mathrm{MI}(\mathrm{n}=90)$ considered that such training was very useful (92.2\%) (Supplementary materials).

\section{Clinical practice and adherence}

There were statistically significant differences regarding the importance of a correct diagnosis and effective therapeutic alternatives between participants trained in MI and professionals trained in AdhE. The professionals trained in MI considered "involving the patient in the treatment plans" $(P<0.05)$, "simplifying the treatment as far as possible" $(P<0.01)$, "giving the patient self-care patterns" $(P<0.05)$ and "performing MI" $(P<0.0001)$ as more important interventions for promoting adherence compared to the professionals trained in AdhE (Figure 3) (Supplementary materials).

\section{Factors affecting adherence}

"Empathy between doctor and patient" and the "concordance of medical and patient treatment goals" were factors that presented a greater influence on the improvement of adherence to asthma treatment for the MI group vs the AdhE group (Supplementary materials).

\section{Adherence and its impact on asthma control (affected areas)}

With regard to the possible affected areas, a higher percentage of professionals trained in AdhE considered that improved adherence to asthma treatment would greatly contribute to a reduction in deaths $(83.3 \%$ vs $64.4 \%, P=0.0062)$ and in direct and indirect costs of asthma ( $56.7 \%$ vs $40.0 \%, P=0.0232)$ compared to professionals trained in MI (Supplementary materials).

\section{Recommendations for improving control and} promoting adherence (useful actions)

MI was regarded as the most valued resource for improving the control and promotion of adherence to asthma treatment, especially for professionals trained in MI. Social media were considered to be useful tools for patients to improve adherence by a higher percentage of professionals trained in $\mathrm{MI}$ than by professionals trained in AdhE (54.4\% vs $31.1 \%$, $P=0.0060$ ) (Supplementary materials).

\section{Discussion}

The main finding of this study is that MI training interventions to promote adherence may positively change clinicians' perspectives on asthma management and promote collaboration-based physician-patient management plans rather than approaches solely centered on education in adherence. However, apart from increasing patients' selfcare and specific importance of MI interventions to improve adherence, no great differences have been detected between doctors trained in MI and trained in AdhE. All the HCPs interviewed in this study also corroborated the relevance of treatment adherence to adequate asthma control.

Similar to previous studies, ${ }^{28,30}$ an inadequate assessment of adherence to asthma medication has been identified. Adherence is frequently evaluated in consultation by patient self-reporting methods with a low implementation of standardized and validated tests. With regard to the impact of training on this question, it seems that a more intensive assessment should be promoted in patients with a major risk of complications. ${ }^{30} \mathrm{HCPs}$ also need to gain a complete understanding of asthma management and the factors that contribute to poor adherence in order to be able to assess the levels of adherence and implement strategies to improve patient self-management and health outcomes. ${ }^{28}$ 


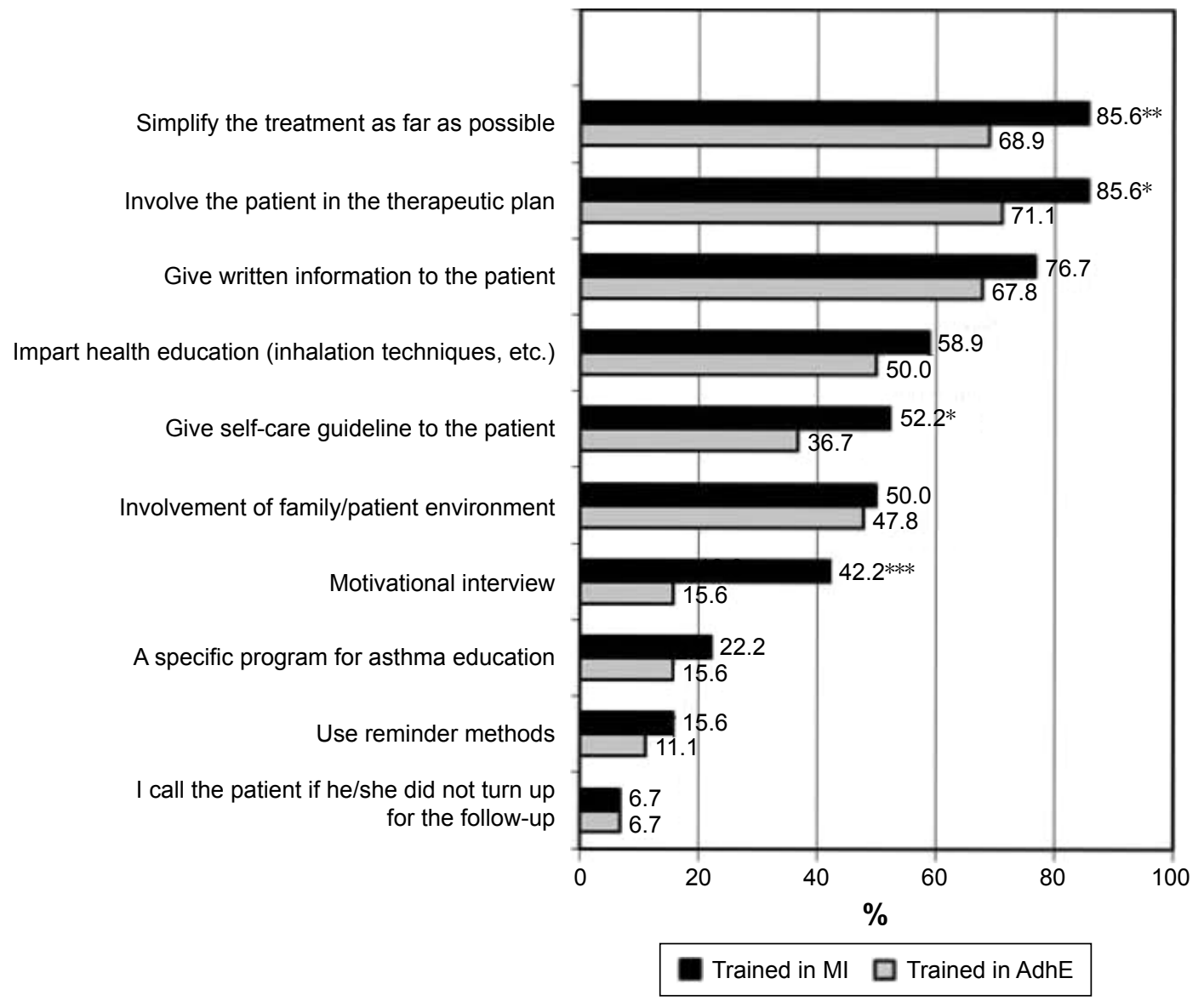

Figure 3 Interventions to promote adherence in participants trained in adherence and participants trained in motivational interviewing. Notes: $* P<0.05 ; * * P<0.01 ; * * * P<0.0001$.

Abbreviations: $\mathrm{Ml}$, motivational interviewing; AdhE, adherence education.

Patients involvement in their understanding of the illness and the risks and benefits of treatment were considered to be the major factors influencing adherence to asthma treatment, which corroborates previous observations. ${ }^{31}$ Clinicians' criteria differ, depending on whether they have been trained in MI or not. In general, trained professionals perceived the concordance of medical-patient goals as a more important factor for adherence than untrained professionals, in accordance with the goals recommended in asthma clinical guidelines. ${ }^{9,32}$ Empathy between physician and patient was considered to be a key issue by clinicians trained in MI. Previous descriptive and pooled analyses generally showed positive effects on consultation processes in a range of measures relating to levels of empathy. ${ }^{33}$ Health care providers' training in specific areas could influence their criteria and attitudes towards patient management.

Currently, there is a paucity of research on interventions specifically designed to improve treatment adherence among asthmatics. To date, the majority of interventions have mainly used educational approaches, although most of these education-based approaches do not address motivation and self-efficacy to engage in a particular behavior. ${ }^{34}$ In a randomized controlled trial, patients with poorly controlled asthma who shared the decision-making process about their treatment showed significantly better adherence to asthma controller medications and to long-acting $\beta$-agonists than patients who participated in either of two control conditions. In that study, negotiating patients' treatment decisions significantly improved adherence to asthma pharmacotherapy and clinical outcomes. ${ }^{35} \mathrm{MI}$ is an intervention that focuses on enhancing 1) intrinsic motivation to engage in a particular behavior and 2) an individual's level of self-efficacy or confidence in his/her ability to engage in that behavior. Brief MI sessions have been shown to improve a variety of health behaviors and health outcomes. ${ }^{36,37}$ However, to our knowledge, to date, no studies have assessed the impact of clinicians using different training methods (MI and AdhE training) to improve adherence in asthmatics. Similarly, this study showed that doctors attending MI training sessions seem to give more importance to patient self-care. 
Good doctor-patient communication promoting discussion about adherence increases patients' willingness to take the medication, although health care providers often feel poorly equipped to provide effective adherence counseling. ${ }^{24}$ Patient-centered approaches to health care during the patient visit are being increasingly more advocated by patients and clinicians and incorporated into training for health care providers. ${ }^{38}$

In this study, according to the HCPs' perceptions, a number of barriers should be overcome before effective adherence interventions could be implemented into health care systems. When doctors were asked for recommendations to promote adherence, their proposals were to increase time for asthma follow-up consultations, to promote professional training in $\mathrm{MI}$, to simplify treatment regimens and to improve patient education, specifically training in the use of inhaler devices by using videos and images. Telemedicine and social media were also suggested as possible tools to improve adherence.

\section{Strengths and limitations}

This study had certain limitations. First, the sample for this study was not obtained through randomization; hence, the results may not be applicable to the whole population of professionals. There were also more female HCPs in MI group, and this can raise the following questions: Are female providers generally considered more empathetic? Did they show a preference for one form of training vs another? Another limitation is that the study investigated attitudes and perceptions only. In addition, our results reflect the attitude/ perception of those who responded to the survey, and may not necessarily represent all professionals in Spain. However, the distribution of the sociodemographic and professional characteristics of our sample presents a fairly homogenous group with a profile that may resemble those found in other national and international studies assessing the possible impact of training interventions to improve asthma medication adherence. We used self-reported, nonvalidated questionnaires for measuring the effect of training on professionals, although the questionnaire may not have adequately measured all factors, and other possible factors may not have been examined. Another limitation of the study is that the educational interventions have been performed in different times, with historical exposure to adherence training vs recent exposure to MI intervention that could lead to more up-to-date information introducing a bias. The opinions could be influenced by being collected right after the MI intervention, and results could have changed if collected after a longer time since the intervention. Besides that, some of the MI-trained people may have had previous AdhE adding a bias to the comparison between those trained in adherence vs those trained in MI. Nevertheless, to our knowledge, this is the first study that specifically assesses the attitudes and perceptions of different HCPs regarding the implications of MI training in adherence in asthma control and behavioral changes. Moreover, the inclusion of professionals from different parts of the country and different medical specialties, and the use of a common protocol may strengthen the results. Only further studies would allow consensus on these results.

\section{Implications for future research}

This study focused on the first step towards implementing training interventions to improve the way professionals integrate adherence and MI into their daily work. Further research into the precise use of training interventions by professionals is required in order to identify which methods are most effective and why. ${ }^{39}$ Another aspect to be addressed is whether and how the use of training interventions affect a patient's attitude towards changing behavior, such as lifestyle and adherence. ${ }^{40}$ Finally, a key challenge is how to achieve sustained improvement over time as most interventions to date have usually been limited to the period of intervention and the goal is widely available and sustainable programs that are cost-effective. ${ }^{41}$

\section{Conclusion}

MI is considered an important tool for promoting adherence to asthma treatment among HCPs, especially by those specifically trained with this methodology. MI training interventions seem to influence HCP's approaches to improve patients' self-care and engagement to treatment plans rather than approaches solely centered on AdhE.

\section{Acknowledgments}

Marta Soria of Adelphi Spain provided assistance for statistical analysis and medical writing under direction from the authors, which was funded by GlaxoSmithKline (GSK).

\section{Disclosure}

The ADHAS Monitor study was a GSK-sponsored study. Lara Ibarrola-Ruiz and Guadalupe Sánchez-Herrero declare that they are full-time employees at the medical department in GSK Spain and hold shares in the company. The other authors report no conflicts of interest in this work.

\section{References}

1. Bourdin A, Halimi L, Vachier I, et al. Adherence in severe asthma. Clin Exp Allergy. 2012;42(11):1566-1574.

2. Bender BG, Rand C. Medication non-adherence and asthma treatment cost. Curr Opin Allergy Clin Immunol. 2004;4(3):191-195. 
3. Krishnan JA, Riekert KA, McCoy JV, et al. Corticosteroid use after hospital discharge among high-risk adults with asthma. Am J Respir Crit Care Med. 2004;170(12):1281-1285.

4. Williams LK, Pladevall M, Xi H, et al. Relationship between adherence to inhaled corticosteroids and poor outcomes among adults with asthma. J Allergy Clin Immunol. 2004;114(6):1288-1293.

5. Lasmar L, Camargos P, Champs NS. Adherence rate to inhaled corticosteroids and their impact on asthma control. Allergy. 2009;64(5):784-789.

6. Bauman LJ, Wright E, Leickly FE, et al. Relationship of adherence to pediatric asthma morbidity among inner-city children. Pediatrics. 2002;110(1 Pt 1):e6.

7. Lee TA, Chang CL, Stephenson JJ, et al. Impact of asthma controller medications on medical and economic resource utilization in adult asthma patients. Curr Med Res Opin. 2010;26(12):2851-2860.

8. Tan H, Sarawate C, Singer J, et al. Impact of asthma, controller medications on clinical, economic, and patient-reported outcomes. Mayo Clin Proc. 2009;84(8):675-684.

9. Guía Española para el Manejo del Asma (GEMA 4.1). Available from: www.gemasma.com. Accessed December 21, 2016.

10. British Thoracic Society, Scottish Intercollegiate Guidelines Network. British guideline on the management of asthma. 2016. Available from: https://www.brit-thoracic.org.uk/document-library/ clinical-information/asthma/btssign-asthma-guideline-2016/. Accessed December 21, 2016.

11. Global Initiative for Asthma (GINA). Global strategy for asthma management and prevention. NHLBI/WHO workshop report. Available from: http://ginasthma.org/gina-reports/. Accessed March 3, 2016.

12. Gamble J, Stevenson M, McClean E, Heaney LG. The prevalence of nonadherence in difficult asthma. Am J Respir Crit Care Med. 2009;180(9):817-822.

13. Desai M, Oppenheimer JJ. Medication adherence in the asthmatic child and adolescent. Curr Allergy Asthma Rep. 2011;11(6):454-464.

14. Haynes RB, Ackloo E, Sahota N, McDonald HP, Yao X. Interventions for enhancing medication adherence. Cochrane Database Syst Rev. 2008;(2):CD000011.

15. Qureshi NN, Hatcher J, Chaturvedi N, Jafar TH; Hypertension Research Group. Effect of general practitioner education on adherence to antihypertensive drugs: cluster randomised controlled trial. $B M J$. 2007;335(7628):1030.

16. Sapkota S, Brien JA, Greenfield JR, Aslani P. A systematic review of interventions addressing adherence to anti-diabetic medications in patients with type 2 diabetes - components of interventions. PLoS One. 2015; 10(6): $\mathrm{e} 0128581$

17. Reisner SL, Mimiaga MJ, Skeer M, Perkovich B, Johnson CV, Safren SA. A review of HIV antiretroviral adherence and intervention studies among HIV-infected youth. Top HIV Med. 2009;17(1):14-25.

18. Easthall C, Song F, Bhattacharya D. A meta-analysis of cognitive-based behaviour change techniques as interventions to improve medication adherence. BMJ Open. 2013;3(8).

19. Nieuwlaat R, Wilczynski $N$, Navarro $T$, et al. Interventions for enhancing medication adherence. Cochrane Database Syst Rev. 2014; (11):CD000011.

20. Irwin RS, Richardson ND. Patient-focused care: using the right tools. Chest. 2006;130(1 Suppl):73S-82S.

21. Miller WR, Rollnick S. Motivational Interviewing: Preparing People for Change. 2nd ed. New York: Guilford Press; 2002.

22. Dunn C, Deroo L, Rivara FP. The use of brief interventions adapted from motivational interviewing across behavioral domains: a systematic review. Addiction. 2001;96(12):1725-1742.

23. Rubak S, Sandbaek A, Lauritzen T, Christensen B. Motivational interviewing: a systematic review and meta-analysis. $\mathrm{Br} \mathrm{J}$ Gen Pract. 2005;55(513):305-312.

24. Lundahl B, Moleni T, Burke BL, et al. Motivational interviewing in medical care settings: a systematic review and meta-analysis of randomized controlled trials. Patient Educ Couns. 2013;93(2):157-168.
25. Broers S, Smets E, Bindels P, Evertsz' FB, Calff M, de Haes H. Training general practitioners in behavior change counseling to improve asthma medication adherence. Patient Educ Couns. 2005;58(3):279-287.

26. Foster JM, Smith L, Usherwood T, Sawyer SM, Reddel HK. General practitioner-delivered adherence counseling in asthma: feasibility and usefulness of skills, training and support tools. J Asthma. 2016;53(3):311-320.

27. Miller WR, Rollnick S. La Entrevista Motivacional: Preparar Para El Cambio de Conductas Adictivas [Motivational interviewing: Preparing people to change addictive behavior]. 10th ed. Barcelona: Paidós Iberia; 1999.

28. Borrelli B, Riekert KA, Weinstein A, Rathier L. Brief motivational interviewing as a clinical strategy to promote asthma medication adherence. J Allergy Clin Immunol. 2007;120(5):1023-1030.

29. Bobes J, Sainz H, Bernando M, Caballero F, Gilaberte I, Ciudad A. Consenso delphi sobre la salud física del paciente con esquizofrenia: valoración por un panel de expertos de las recomendaciones de las sociedades españolas de psiquiatría y de psiquiatría biológica [Dephi consensus on the physical health of patients with schizophrenia: evaluation of the recommendations of the spanish societies of psychiatry and biological psychiatry by a panel of experts]. Actas Esp Psiquiatr. 2012;40(3):114-128.

30. Lim KG, Rank MA, Li JT, et al. How well does patient self-report predict asthma medication possession? Implications for medication reconciliation and adherence assessment. J Asthma. 2010;47(8):878-882.

31. Haughney J, Price D, Kaplan A, et al. Achieving asthma control in practice: understanding the reasons for poor control. Respir Med. 2008;102(12):1681-1693.

32. Department of Health, UK. An Outcomes Strategy for Chronic Obstructive Pulmonary Disease (COPD) and Asthma in England. 2011. Available from: https://www.gov.uk/government/uploads/system/uploads/attachment_data/file/216139/dh_128428.pdf. Accessed February 26, 2016.

33. Horne R, Chapman SC, Parham R, Freemantle N, Forbes A, Cooper V. Understanding patients' adherence-related beliefs about medicines prescribed for long-term conditions: a meta-analytic review of the necessity-concerns framework. PLoS One. 2013;8(12):e80633.

34. Dwamena F, Holmes-Rovner M, Gaulden CM, et al. Interventions for providers to promote a patient-centred approach in clinical consultations. Cochrane Database Syst Rev. 2012;(12):CD003267.

35. Wilson SR, Strub P, Buist AS, et al; Better Outcomes of Asthma Treatment (BOAT) Study Group. Shared treatment decision making improves adherence and outcomes in poorly controlled asthma. Am J Respir Crit Care Med. 2010;181(6):566-577.

36. Lozano P, Finkelstein JA, Carey VJ, et al. A multisite randomized trial of the effects of physician education and organizational change in chronic-asthma care: health outcomes of the Pediatric Asthma Care Patient Outcomes Research Team II Study. Arch Pediatr Adolesc Med. 2004;158(9):875-883.

37. Rollnick S, Miller WR, Butler CC. Motivational Interviewing in Health Care: Helping Patients Change Behavior. New York: Gilford Press; 2008.

38. Rubak S, Sandbaek A, Lauritzen T, Borch-Johnsen K, Christensen B. An education and training course in motivational interviewing influence: GPs' professional behaviour - ADDITION Denmark. Br J Gen Pract. 2006;56(527):429-436.

39. Tanana M, Hallgren KA, Imel ZE, Atkins DC, Srikumar V. A comparison of natural language processing methods for automated coding of motivational interviewing. J Subst Abuse Treat. 2016;65:43-50.

40. Keep SM, Reiffer A, Bahl TE. Supporting self-management of asthma care. Home Healthc Now. 2016;34(3):126-134.

41. Boland MR, Kruis AL, Tsiachristas A, et al. Cost-effectiveness of integrated COPD care: the RECODE cluster randomised trial. $B M J$ Open. 2015;5(10):e007284. 


\section{Publish your work in this journal}

Patient Preference and Adherence is an international, peer-reviewed, open access journal that focuses on the growing importance of patient preference and adherence throughout the therapeutic continuum. Patient satisfaction, acceptability, quality of life, compliance, persistence and their role in developing new therapeutic modalities and compounds to optimize

clinical outcomes for existing disease states are major areas of interest for the journal. This journal has been accepted for indexing on PubMed Central. The manuscript management system is completely online and includes a very quick and fair peer-review system, which is all easy to use. Visit http://www. dovepress.com/testimonials.php to read real quotes from published authors.

Submit your manuscript here: http://www.dovepress.com/patient-preference-and-adherence-journal 